\title{
Erratum to: Assessment of FDG retention differences between the FDG-avid benign pulmonary lesion and primary lung cancer using dual-time-point FDG-PET imaging
}

\author{
Koichiro Kaneko • Eiji Sadashima • \\ Koji Irie · Akihiro Hayashi · Satoru Masunari · \\ Tsuyoshi Yoshida $\cdot$ Junichi Omagari
}

Published online: 17 July 2013

(C) The Japanese Society of Nuclear Medicine 2013

Erratum to: Ann Nucl Med (2013) 27:392-399

DOI 10.1007/s12149-013-0698-4

The author would like to correct the misspelled name of the co-author in the published article. The correct name should be "Eiji Sadashima" not "Shinji Sadashima".

The online version of the original article can be found under doi:10.1007/s12149-013-0698-4.

K. Kaneko $(\bowtie) \cdot$ T. Yoshida

PET Imaging Center, Koga Hospital 21, 3-3-8 Miyanojin,

Kurume 839-0801, Japan

e-mail: kkaneko-kyu@umin.ac.jp

E. Sadashima $\cdot$ K. Irie

Department of Pathology, Shin Koga Hospital, 120 Tenjin-chou,

Kurume 830-8577, Japan

\section{A. Hayashi}

Department of Respiratory Surgery, Shin Koga Hospital,

120 Tenjin-chou, Kurume 830-8577, Japan

S. Masunari · J. Omagari

Department of Radiology, Koga Hospital 21, 3-3-8 Miyanojin,

Kurume 839-0801, Japan 